\section{How to be a centre of excellence}

SIR - John Maddox (Nature 366, 717; 1993) presents four basic reasons for the success of the Japanese Institute for Space and Astronautical Science (ISAS). I was reminded immediately of a British research institute which up to about 20 years ago fitted his criterion quite closely. It was (1) autonomous and tightly run, (2) relied on science and engineering equally for its success, (3) was human in scale $(100-150$ staff) and (4) staff of all grades worked closely together to get the practical work done. This institute was called the National Institute of Oceanography (NIO). The neutrally buoyant deep-ocean float and the GLORIA side-scan survey instrument were among its developments. In the 1980 s, under contract to the US Geological Survey, GLORIA was used successfully to survey an area roughly equal to that of the continental United States with a down-time from all causes (mainly bad weather) of less than 5 per cent. After 20 years, this instrument is still capable of regularly producing surprising discoveries, and its development continues.

In 1960, about two layers of administration were needed for the director of the NIO to obtain support to build the research vessel RSS Discovery. In Britain today, a decision of similar relative size may require nine or more layers. This increase in complexity has been caused in the main by an entirely laudable desire to ensure accountability for public money spent on research.

Instead, it has diffused accountability, and tends to turn the efforts of good people at all levels away from active science and into administration. The situation cries out for flatter structures, with real authority and accountability delegated as closely as possible to the researcher at the bench or in the field.

An active university research supervisor can train in his working lifetime many times the number of new researchers required to maintain a steady-state population. This may not always be appropriate. When this is the case, or when a field of research requires longterm planning or has relatively high infrastructure costs, the research institute can be an appropriate way to meet these special needs. However, research institutes cannot flourish without close university contacts. The late Roger Revelle, who was a great director of the Scripps Institute of Oceanography, is recorded as having said that a marine institute not linked to a university could expect to survive only one generation. He would be pleased that the Institute of Oceanographic Sciences (successor to the NIO) is now being integrated into a much larger marine centre at the University of Southampton. This development, along with similar changes occurring at other marine institutes, should be of considerable benefit to British marine science. Its management structure is now being determined. The lessons Maddox draws from the successful operation of just such a university-based research institute in Japan could be applied in Britain to very useful effect. To recapitulate, these include a really meaningful autonomy, a close integration of pure science with applied disciplines (especially engineering) and an open human-scale community with a flat structure allowing active involvement in research at all levels of the organization.

\section{T. Roger S. Wilson}

Firbank,

Portsmouth Road,

Milford,

Godalming, Surrey GU85DR, UK

\section{Of sound mind}

SIR - J. R. Smythies ${ }^{1}$ states that Canon C. E. Raven told him that Wittgenstein "suffered from paranoid delusions". Smythies then elaborates on a "speech disorder known as schizophreneze". Smythies says that he attend[ed] the weekly meetings of Wittgenstein's disciples and found the "thoughts produced" by this group "very like the thoughts and mode of thinking that troubled my schizophrenic patients".

On 12 November 1993, we interviewed Smythies' claims ${ }^{2}$. Moore was professor of psychiatry at Trinity College, Dublin, and the leading Irish psychiatric clinician of his day. In the late 1940s, Wittgenstein had been referred to Moore for 'another opinion' by Dr Maurice Drury, a psychiatrist working at St Patrick's Hospital in Dublin, and a friend of Wittgenstein. Drury, according to Moore, "was worried" about Wittgenstein, who was on one of his extended visits to Ireland. Unlike Smythies, who had "no personal contact with Wittgenstein", Moore saw Wittgenstein about five or six times in St Patrick's Hospital. Moore categorically stated to us that Wittgenstein was not a schizophrenic. Moore described Wittgenstein when he saw him as a "depressed and sad man", who was "down with depressed affect" and "gloomy", that he spoke "slowly" and was "slowed down".

There is extensive evidence of Wittgenstein's depressive moods, as is clear from Ray Monk's careful biographical study of Wittgenstein. Thus Monk ${ }^{3}$ quotes Wittgenstein writing to Rush Rhees: "First suffered terrible depressions." Later Monk $^{3}$ talks about Wittgenstein's "depression as Christmas approaches". There Professor Norman Moore about is no doubt that Wittgenstein was a sensitive, highly strung personality, whose interpersonal relations could be difficult; and indeed Moore describes him as such. But Moore was certain that Wittgenstein showed no signs of schizophrenia. We think this evidence is important, as Moore seems to have been the only psychiatrist to interview and perhaps treat Wittgenstein in a professional capacity.

Smythies' evidence that Wittgenstein suffered from thought disorder or paranoid delusions amounts to little more than gossip or hearsay. The only person who was schizophrenic in the inner Wittgenstein circle, according to $\mathrm{Monk}^{3}$, was Yorick Smythies, who "suffered from paranoid schizophrenia and became a patient of Maurice Drury. He died in tragic circumstances in 1981."

Michael Fitzgeraid

David Berman

Department of Psychiatry,

Department of Philosophy,

Trinity College,

Dublin, Ireland

1. Smythies, J. R. Nature 350, 9 (1991)

2. Fitzgerald, M. \& Berman, D. Taped interview with Norman Moore (Dublin, 12 November 1993).

3. Monk, R. The Duty of Genius (Jonathan Cape, London, 1990).

\section{Creative budgeting}

SIR - In David Dickson's report "UK councils face $£ 7.5$ million efficiency cuts" (Nature 367, 501; 1993) he refers to "'new money' provided by the Treasury".

Good news? Well perhaps, but we should be careful to distinguish 'spin' from fact in government presentations. The spending plans announced in November 1992 foresaw a budget for science staying approximately constant in real terms until 1994-95 and then falling in 1995-96. In November 1993, Save British Science welcomed the budget statement demonstrating that William Waldegrave's promise to maintain the value of the science budget had been kept, and extended to 1995-96.

There is no "new" money. After the November 1993 statement, a provisional, but unannounced, carve-up between the research councils was made in which $£ 9$ million was left unallocated. Of this sum, $£ 7.5$ million (leaving $£ 1.5$ million for next month's 'new money'?) has been added to John Cadogan's 'efficiency savings' of $£ 7.9$ million (so far unidentified) to make the $£ 15.4$ million in question.

John Major, in his 'back to basics' speech on science, has promised a 'real' increase for science next year. Had we seen the small real increase promised in 1991 , science would already be about $£ 40$ million a year better off.

\section{J. H. Mulvey}

Save British Science Society,

Box 241,

Oxford $O X 13 Q Q, U K$ 